\title{
The systematic approach to designing energy efficient cities
}

\author{
Yaroslav Shchenikov ${ }^{1, *}$ \\ ${ }^{1}$ Saint-Petersburg state university of Aerospace Instrumentation, 195000 Bolshaya Morskaya st., 67A, Russian Federation
}

\begin{abstract}
The novelty of the proposed paper lies in the use of elements of the theory of solving inventive problems TRIZ and the systems theory to achieve the maximum positive synergistic effect of the correct Association of city residents and urban systems.
\end{abstract}

\section{Introduction}

The importance of improving cities' energy efficiency is confirmed by numerous studies aimed at ensuring economic growth and solving social problems in order to make life as comfortable, high-quality and safe as possible for urban residents [1,2].

For the Russian Federation, such problems as seasonal affective disorder (seasonal depression), safety and convenience of the urban environment for children and people with disabilities, poor ecology, significant loss of time for transportation, large losses of heat energy in buildings are particularly relevant for cities.

Recently, there have been problems in the urban environment related to the increasing use of personal electric vehicles, as well as unmanned aerial vehicles. The COVID-19 pandemic and the need to ensure social distance through various technical means.

Therefore, it is very important to put forward and develop new principles and approaches to the problem of improving the modern cities' energy efficiency.

The buildings' energy efficiency is inextricably linked to the energy efficiency of the cities in which they are located.

The story of increasing energy efficiency in cities probably begins with King Gillette's book «The Human Drift», published back in 1894, in which he proposed the idea of the «Metropolis» - house-city designed for a huge number of residents [3]. There are projects of similar buildings-cities in the USSR, for example, the project of a house for a million inhabitants from academician Abram Ioffe (fig.1). For a number of reasons, these projects are utopian, being dependent on the risks of fire or, for example, an earthquake. In addition, humanity is not yet ready to completely relocate to this kind of city-building.

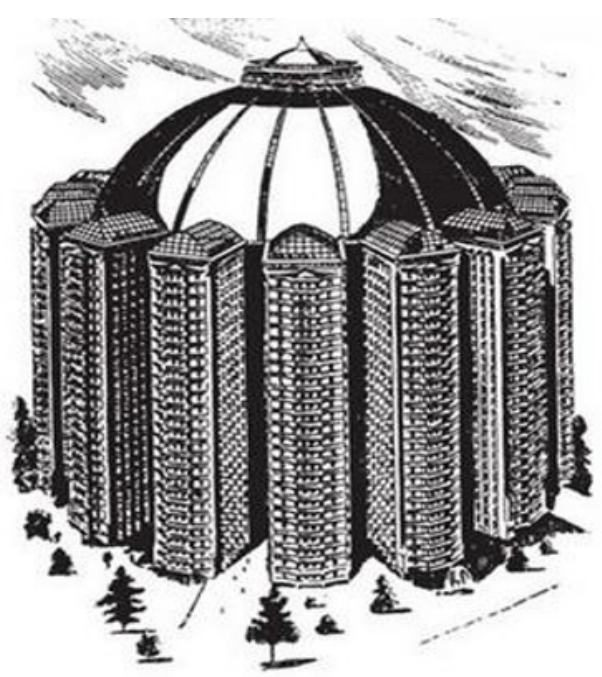

Fig. 1. Abram Ioffe's project of the building-city.

There are also known Soviet projects of Arctic cities in the middle of the XX century, one of which partially realized in Udachny town in Yakutia (fig. 2).

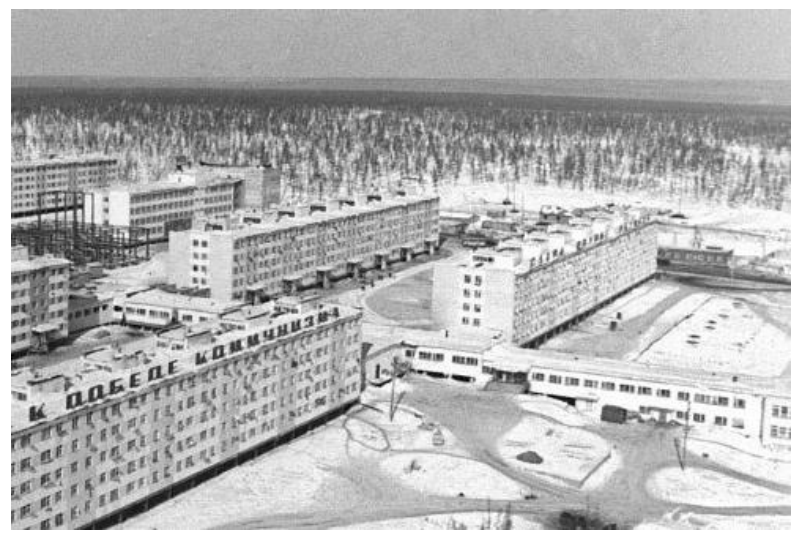

Fig. 2. The covered gallery in Udachny city (Yakutia).

\footnotetext{
* Corresponding author: yar2409@mail.ru
} 


\section{Materials and methods}

This paper suggests using the laws and principles of the theory of inventive problem solving (TRIZ) and the systems theory to ensure the cities' energy efficiency [4].

Complex socio-technical systems, which include cities, do not lend themselves well to mathematical modeling due to the presence of subsystems that are modeled in various simulation paradigms. For example, it is advisable to conduct traffic modeling using the agent-based modeling paradigm, and heat transfer using the system dynamics paradigm.

Models have not yet been developed that would make it possible to comprehensively assess the safety of the urban environment, taking into account the influence of all factors affecting urban safety.

\section{Results}

In a city, as in a large socio-technical system, there are many options for implementing a positive synergistic effect. The examples are provided below.

Using the townspeople warmth. Each person emits heat energy of the order of $100 \ldots 120 \mathrm{~W}$ when sitting at rest, $150 \ldots 220 \mathrm{~W}$ when moving and when working lightly, 300...430 W when walking fast and doing active physical activity. With a large crowd of moving people, you can get quite a large amount of thermal energy, if you do not disperse it into the atmosphere (figure 3 ).

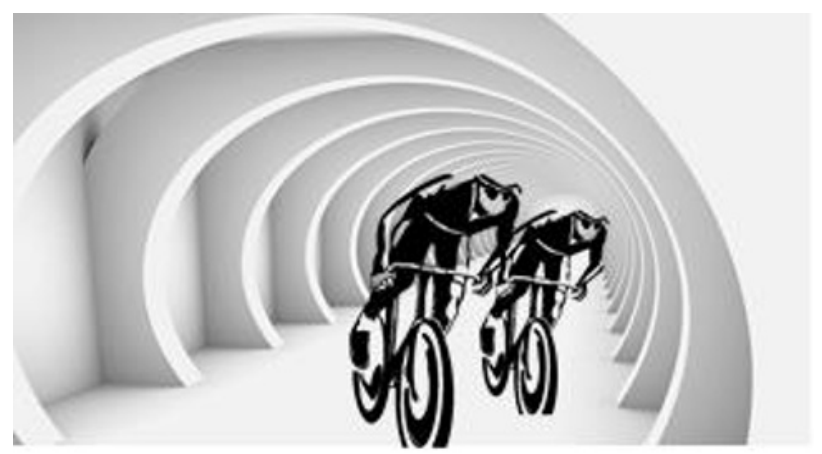

Fig. 3. The "cyclist - heat-insulated bike path" system's positive synergistic effect.

Make the most of the environment's free energy, in particular the sun. Combining in one system the generation and distribution of heat energy of such subsystems as a building, a solar collector and a district heating plant can maximize a positive synergistic effect, in contrast to the case when these subsystems would be used independently of each other (Figure 4).

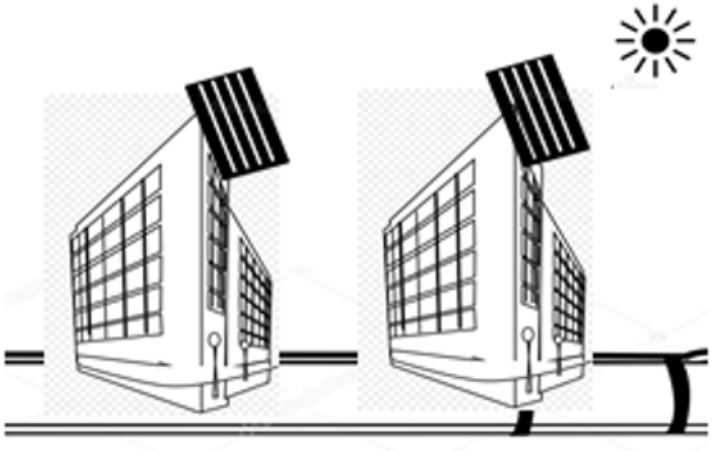

Fig. 4. The "building - solar collector - heating plant" system's positive synergistic effect.

For the cities of the Russian Federation, the centralized heat supply system is both a disadvantage and an advantage. On the one hand, accidents occur quite often, so it is necessary to maintain the network in working order, on the other hand, this makes it possible to redistribute excess heat energy from buildings with an excess of it to buildings with a lack of it. Also in the event of an emergency, you can provide energy to buildings via backup paths. Reuse or even reuse and store thermal energy before it is released into the environment.

It is advisable to use surplus electricity to ensure the year-round life of green spaces placed inside buildings and structures. It is even possible to create small "rivers" and "seas" inside the city for the rest of the townspeople.

Synergistic effect of combining several city services. For example, a city streets cleaning robot can additionally act as an observer to assist police, nonurgent transportation of objects and citizens with limited mobility (Figure 5).

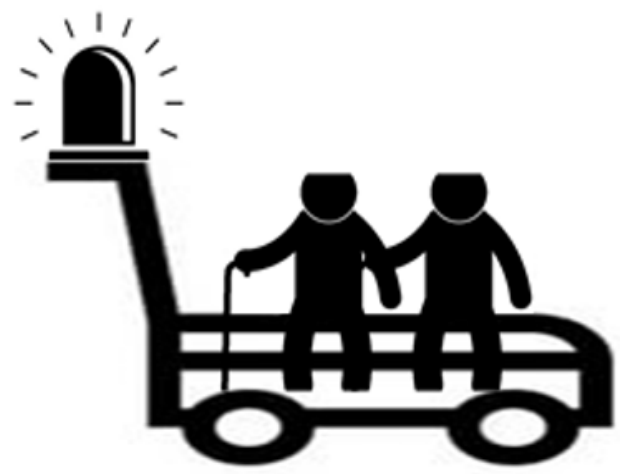

Fig. 5. The "police robot - cleaning robot - transport robot" system's positive synergistic effect.

Traffic flows diversity. Environmental pollution of cities is largely determined by the level of gas pollution in the streets, which, in turn, depends on the intersection of traffic flows (traffic jams). Recently and already, perhaps, personal electric transport and unmanned aerial vehicles for the transport of goods have become permanently entrenched, which also require the allocation of specialized transport corridors that do not intersect with traditional transport flows.

Use of modern innovative technologies, for example, sensor networks. As the technology of sensor networks 
develops and becomes cheaper, even greater positive synergies can be predicted due to the urban services digitalization and intellectualization $[5,6]$.

\section{Discussion}

However, the risks are forcing the construction of energy efficient distributed city-buildings. The project of such a building-city should be a system of energy-efficient city blocks, connected by energy-efficient transport routes with a minimum of traffic jams. It is easier to conserve heat when not consumed.

Improving the energy efficiency of cities will require large financial costs, but these costs can be quickly recouped by saving and recycling energy resources.

\section{Conclusion}

In the Russian Federation, many buildings are in need of repair and modernization, the power grids in small cities also need modernization - all this provides an excellent opportunity to revise the development plan for Russian cities.

Now modern knowledge and technologies already allow the construction of buildings and cities that are much more efficient in terms of energy efficiency.

Old Arctic cities' projects with minor alterations and the use of modern construction and information technologies can be used in the construction of energy efficient cities for areas with a more favorable climate.

New technologies bring new opportunities to improve the energy efficiency of cities. These technologies must be used with maximum synergistic effect.

\section{References}

1. M. Jenks, Dimensions of the Sustainable City (Springer, 2010)

2. Energy and Urban Innovation / World Energy Council (London, 2010) http://www.worldenergy.org/publications/defau lt.asp.

3. King Camp Gillette, The Human Drift (New Era Publishing, 1894)

4. I. L. S Sheng,. T. Kok-Soo,. "Eco-Efficient Product Design Using theory of Inventive Problem Solving (TRIZ) Principles". American Journal of Applied Sciences, 7 (6), 852-858. doi:10.3844/ajassp.2010.852.858. (2010)

5. T. Aoe, S. Kurihara, O. Namikawa, T. Takahashi and C. Nakaniwa, 2005. Publication of the ecoefficiency Handbook in 2004 Ecoefficiency, Project in Japan. Proc. 4th International Symposium on Environmentally Conscious Design and Inverse Manufacturing, Dec.12-14, IEEE Xplore Press, USA., pp: 764765. DOI: 10.1109/ECODIM.2005.1619344
6. Silvia Liberata Ullo, G.R. Sinha (2020-05-31). "Advances in Smart Environment Monitoring Systems Using IoT and Sensors". Sensors (Basel, Switzerland). 20(11):3113. doi:10.3390/s20113113.

7. N. Ketoeva, N. Soldatova, N. Rebrikova, and S. Ilyashenko, Russian Hydropower Sector and its Human Resources Under Digitization Conditions,IOP Conference Series: Materials Science and Engineering, 497(1), 012121 (2019) doi:10.1088/1757-899X/497/1/012121 